\title{
Depression is Associated with Moderate-Intensity Physical Activity Among College Students During the COVID-19 Pandemic: Differs by Activity Level, Gender and Gender Role
}

This article was published in the following Dove Press journal:

Psychology Research and Behavior Management

\author{
Jingyuan Lin, (ID) I,* Tianyou Guo, ${ }^{2, *}$ \\ Benjamin Becker, (iD) ${ }^{3}$ Qian Yu, (iD) ${ }^{2}$ \\ Si-Tong Chen, ${ }^{4}$ Stubbs Brendon, ${ }^{5}$ \\ Md Mahbub Hossain, (ID) \\ Paolo M Cunha, (iD ${ }^{7}$ \\ Fernanda Cunha Soares, ${ }^{8}$ \\ Nicola Veronese, 9 Jane Jie Yu, (D ${ }^{10}$ \\ Igor Grabovac, " Lee Smith, ${ }^{2}$ \\ Albert Yeung, ${ }^{13}$ Liye Zou, (iD ${ }^{2}$ \\ Hong Li (iD)
}

'Research Centre of Brain Function and Psychological Science; Center for Language and Brain, Shenzhen Institute of Neuroscience; Shenzhen Key Laboratory of Affective and Social Cognitive Science, School of Psychology, Shenzhen University, Shenzhen, 5I8060, People's Republic of China; ${ }^{2}$ Exercise and Mental Health Laboratory, School of Psychology, Shenzhen University, Shenzhen 518060 , People's Republic of China; ${ }^{3}$ The Clinical Hospital of Chengdu Brain Science Institute, MOE Key Laboratory for Neuroinformation, University of Electronic Science and Technology of China, Chengdu 610054, Sichuan, People's Republic of China; ${ }^{4}$ Institute for Health and Sport, Victoria University, Melbourne, VIC, 800I, Australia; ${ }^{5}$ Department of Psychological Medicine, Institute of Psychiatry, Psychology, and Neuroscience, King's College London, London, UK; ${ }^{6}$ Department of Health Promotion and Community Health Sciences, School of Public Health, Texas A\&M University, College Station, TX 77843, USA. ${ }^{7}$ Me Station, TX 77843, USA, Metabolism, Nutrition, and Exercise Laboratory, Londrina State University, Londrina, Paraná 860 I0-580, Brazil; ${ }^{8}$ Superior School of Physical Education, University of Pernambuco, Recife, PE, Brazil; ' ${ }^{9}$ Geriatric Unit, Department of Internal Medicine and Geriatrics, University of Palermo, Palermo 90100, Italy; ${ }^{10}$ Department of Sports Science and Physical Education, The Chinese University of Hong Kong, Shatin, New Territories 999077

Hong Kong; " 'Department of Social and Preventive Medicine, Center for Public Health, Medical University of Vienna, 1090 Wien, Austria; ${ }^{12}$ The Cambridge Centre for Sport and Exercise Sciences, Anglia Ruskin University, Cambridge CBI IPT, UK; ${ }^{13}$ Depression Clinical and Research Program, Massachusetts General Hospital, Boston, MA 02114, USA

*These authors contributed equally to this work

Correspondence: Hong $\mathrm{Li}$

Research Centre of Brain Function and Psychologica Science; Center for Language and Brain, Shenzhen Institute of Neuroscience; Shenzhen Key Laboratory of Affective and Social Cognitive Science, School of Psychology, Shenzhen University, Shenzhen 518060,

People's Republic of China

Email lihongwrm@vip.sina.com
Purpose: The novel coronavirus disease (COVID-19) pandemic and associated restrictive measures have implications for depressive symptoms (henceforth depression) of young people and risk may be associated with their reduced physical activity (PA) level. Therefore, we aimed to examine the association between depressive symptoms and PA among college students with different gender and gender role (masculinity traits and femininity traits) during the COVID-19 pandemic.

Participants and Methods: Cross-sectional study included 628 healthy college students from nineteen different locations. The Center for Epidemiological Studies Depression Scales (CES-D), the International Physical Activity Questionnaire - Short Form (IPAQ-SF), and the 50-item Chinese Sex-Role Inventory (CSRI-50) were used to measure depressive symptoms, PA continuous (weekly metabolic equivalent minutes, MET-minutes/week) and categorical indicators (activity level category) and gender role, respectively. The statistical analyses were used in partial correlation analysis, $t$-test, one-way ANOVA, moderation model tests, and linear regression model tests.

Results: Total of $34.72 \%$ participants had clinically relevant depression (16, CES-D scale). Total of $58.6 \%$ participants were classified as a "low" activity level for spending less time on PA. Depression significantly negatively correlated with MET-minutes/week in moderateintensity PA but not vigorous and walking scores. Of note, the depression-PA association was only moderated by the "low" activity level group in terms of categorical scores across gender groups. Participants with higher masculinity traits were less likely to have depression among all participants. Moreover, more recovered cases and fewer deaths could also predict the lower depression risk in the "high" activity level group.

Conclusion: Moderate-intensity PA is beneficial for reducing depression risk among college students at a low activity level. College students with fewer masculinity traits (regardless of gender) are highly vulnerable to depression during the outbreak of COVID-19. Effective control of the COVID-19 pandemic seems critical to alleviating the burden of mental disorders of the public including depression.

Keywords: depression, physical activity, gender, masculinity, femininity, COVID-19

\section{Introduction}

The Novel Coronavirus disease (COVID-19) has formally been considered as a global pandemic on 11th March 2020. ${ }^{1}$ Given its high person-to-person transmission rate, multiple appropriate measures (eg, social distancing, quarantine, and 
isolation) were implemented across the world. ${ }^{2}$ Such major lifestyle changes during times of enormous uncertainty have been found to associate with mental health problems such as a higher risk of depression ${ }^{3-5}$ during the COVID-19 pandemic. Depression is a major mental disorder with symptoms including exaggerated and persistent sadness, anhedonia, cognitive impairments, and a negative procession bias as well as somatic symptoms (insomnia and fatigue). ${ }^{6}$ More than 322 million people worldwide are currently experiencing clinically relevant depression $^{7}$ and would become one of the leading causes of disability worldwide by $2030 .{ }^{6,8}$ The risks for increasing levels of depression associated with the COVID-19 pandemic must, therefore, be considered as a major global health issue of increasing relevance., ${ }^{9,10}$

Compared with the prevalence of depression (3.6\%) among young people (18-34 years) in a cross-sectional study conducted by the China Mental Health Survey (CMHS) in 2019, ${ }^{11}$ the risk of depression in Chinese young adults $(22.1 \%)$ and college students $(23.3 \%)$ have steeply risen during the COVID-19 pandemic. $^{12,13}$ Increased levels of depressive symptomatology up to clinically relevant levels of depression have not only been found among patients and healthcare professionals (eg, surgical staff, medical doctor, and nurse) but also in the general population. ${ }^{14,15}$ In addition to healthcare professionals, young people were generally more likely to experience strongly increased levels of depression during the pandemic. ${ }^{13}$ Moreover, students who were affected by prolonged school closure may experience severe psychological stress, ${ }^{16}$ which may increase the likelihood of depression. Collectively, the currently available data suggest that college students are at an increased vulnerability to developing depression during the COVID-19 pandemic. ${ }^{9,12,17-19}$

Previous studies demonstrated that lower levels of depression were associated with more time spent on physical activity (PA) including team sports, gym exercises, and outdoor walking. ${ }^{20-22}$ Also, a recent large-scale metaanalysis of prospective cohort studies suggested that fewer depressive symptoms were associated with more frequent PA regardless of age and geographical region. ${ }^{23}$ Of note, these studies were not conducted during the COVID-19 pandemic when the public was recommended to isolate themselves and minimize public gatherings. In this context, it is obvious that people have to change their regular exercise patterns (eg, outdoor sports, gym exercises, and team sports). Although exercise scientists have discussed the detrimental impacts of the COVID-19 pandemic on $\mathrm{PA},{ }^{24-27}$ how those effects reflected in Chinese youth is still unclear.

Considering that more people might spend less time on PA during the COVID-19 pandemic, we further investigated the association of depression with PA across participants with different activity levels (low, moderate, and high) like previous studies did. ${ }^{23}$ On the other hand, the risk of depression was commonly observed to be higher in females than males, ${ }^{28}$ but the frequency of PA was generally lower in females than males, ${ }^{29}$ thus we considered gender as a potential moderator. Besides, accumulate studies suggested that psychosocial gender (gender role: masculinity and femininity traits) could be a sensitive indicator to interpret both mental and physical health among general populations. ${ }^{30,31}$ A well-known gender-role opinion suggested that everyone has two clusters of independent and orthogonal masculine (eg, dominant, has leadership abilities, and competitive, etc.) and feminine traits (eg, understanding, warm and compassionate, etc.), regardless of gender. ${ }^{32,33}$ Of note, people with greater orientation in masculinity and femininity were found experienced lower depressive symptoms than those with lower masculinity and femininity level. ${ }^{30}$ Besides, adolescent girls who increased their physical activity were also higher in masculinity and femininity than physically inactive girls with unhealthier mental functioning. ${ }^{34}$ In this regard, gender role was also considered as a potential moderator in the association of depression and PA.

Collectively, this study aimed to investigate associations between depression and PA among Chinese college students and to examine the effect of gender and gender role on such relationships during the COVID-19 pandemic. Results of this study would provide references for health professionals and governments to engage in PArelated intervention programs for college students with different risks of depression during the pandemic.

\section{Methods}

This study used a cross-sectional design. Data were collected between the 10th to 16th, March in 2020. At that time, the lockdown policies have been implemented in almost all regions of China as a measure to regulate infection rates. ${ }^{35}$ Of note, all colleges and universities in China closed at that time. All participants took part in this study voluntarily with a written informed online consent form. Each participant was remunerated with CNY10.0 (approximately 1.5 US dollars) upon the completion of 
their participation. This study was approved by the Human Research Ethics Committee (No: 2,020,005) of Shenzhen University in accordance with the Declaration of Helsinki.

\section{Participants}

A total of 628 healthy Chinese college students (64.8\% females, mean aged $( \pm \mathrm{SD}) 20.17( \pm 1.87)$ years $)$ without any symptoms related to the COVID-19 participated in this survey distributed through social media (WeChat) app (https://www.wechat.com/en/), which is one of the most popular online social platforms in China connecting a billion people with free calls and chats. People can access to the survey links from their individual or group chats and advertisement pages of this platform with convenience. All participants (freshmen $=309$, sophomore $=$ 143 , junior $=75$, senior $=86$, and post-graduate $=15$ ) lived in nineteen different locations across China. Three participants who missed their location information were excluded, leading a final sample size of 625 participants for statistical analyses.

\section{Measures}

\section{Physical Activity}

The International Physical Activity Questionnaire-Short Form (IPAQ-SF) is a widely used instrument developed by the International Consensus Group on Physical Activity Measurement to measure physical activity in adults. ${ }^{36,37}$ The original questionnaire was translated and validated in Chinese. ${ }^{38,39}$ The IPAQ-SF consists of 6 items about varies dimensions of PA include walking, moderate-intensity (eg, carrying light loads, bicycling at a regular pace) and vigorous-intensity (eg, heavy lifting, digging, aerobics) activity in terms of both the duration (in minutes/day) and frequency (days/week) and one item about the duration (in minutes/day) of sedentary. According to the guidelines for data processing and analysis, ${ }^{40}$ both continuous (the Metabolic Equivalent of Task-minutes/week (MET-m/ w) for walking, moderate-, vigorous-intensity, and sitting activity) and categorical indicators (low, moderate, and high activity level) of PA are possibly obtained from IPAQ-SF after a raw data processing procedure (see Supplementary Appendix 1) recommended by the IPAQ group. For the continuous indicators, scores in each activity could be processed into the MET-m/w using MET values for sitting (1.0 MET), walking (3.3 METs), moderate-intensity (4.0 METs), and vigorous-intensity (8.0 METs). For example, if someone spent 45 minutes/day for moderate-intensity PA during last 7 days, his moderate- intensity PA MET-m/w would be 1039.5 via a formula $($ MET-m/w $=$ MET-value * minutes * days). For the categorical indicators, participants can be categorized into "low" activity level (LAL), "moderate" activity level (MAL), or "high" activity level (HAL) categories using the published criterion (see Supplementary Appendix 2) recommended by the IPAQ group. In the current study, both MET-m/w and activity levels were regarded as PA indices.

\section{Depressive Symptoms}

Depressive symptoms were measured using the selfreported Center for Epidemiological Studies Depression Scales (CES-D) in Chinese with good reliability and validity of Cronbach's alpha coefficients of 0.90 for full scale. $^{41,42}$ It consists of 20 items within four dimensions (depressed affect, positive affect, somatic complaints, and interpersonal problems). ${ }^{43}$ Each item can be scored on a 4-point Likert scale $(0=$ rarely or not at all to $3=$ most of the time). In this regard, individuals can obtain a maximum of 60 points, with higher scores indicating more severe depression. In the present study, the Cronbach's alpha coefficients were $0.95,0.88,0.84,0.83$, and 0.79 for the full scale of CES-D, depressed affect, positive affect, somatic complaints and interpersonal problems subscales, respectively. The continuous scores in CES-D scale were adopted as depression indices.

\section{Gender Role}

Gender-role traits were measured using the 50-item Chinese Sex-Role Inventory (CSRI-50). ${ }^{44}$ It included three dimensions related to masculinity (eg, leadership, rationality, and generosity, etc.), femininity (eg, empathy, thrift, and careful, etc.), and neutral traits. Each item is scored from 1 (never or almost never true) to 7 (almost always or always true), with higher scores in masculinity or femininity indicating more masculine or feminine traits. Additionally, continuous gender-role scores can be classified into four gender-role identities (masculine $=$ high in masculinity and low in femininity, feminine $=$ high in femininity and low in masculinity, androgynous = both high in masculinity and femininity, and undifferentiated $=$ both low in masculinity and femininity) based on the median of distributions of masculinity and femininity scales. In the present study, Cronbach's alpha coefficients were 0.91 and 0.88 for items on masculinity and femininity subscales, respectively. The recommended median score of masculinity (4.8) and femininity (5.0) subscales 
were adopted in this study. ${ }^{44}$ Also, both gender-role continuous scores and categories were regarded as gender-role indices.

\section{Demographic Variables and COVID-19 Data}

Demographic data were also collected, including gender, age, grade, and location of current residence. In addition, from the official website of the National Health Commission in China, ${ }^{45,46}$ we had extracted data related to the COVID-19, such as the number of new cases, confirmed cases, recovered patients, and death toll, which was matched with location of participants and the date when they filled out the questionnaire.

\section{Statistical Analysis}

Step 1: Pearson correlation analyses were performed to investigate associations of depression (sum scores of the full scale) with MET-m/w in different levels (walking, moderate-intensity, and vigorous-intensity) of PA and sedentary activity. Significant associations of depression and PA were further investigated in terms of four dimensions of the CES-D when controlling for age, grade, sedentary MET-m/w, and the COVID-19-related data using partial correlation analyses.

Step 2: Between-group differences on PA MET-m/w (walking, moderate-intensity, vigorous-intensity, and sedentary activity) and depression were tested across gender (female and male), and gender-role identities (undifferentiated, androgynous, masculine, and feminine identity). Likewise, we further tested between-group differences in depression across activity levels (LAL, MAL, and HAL). This is followed by moderation analyses where the CES-D score, MET-m/w (walking, moderateintensity, vigorous-intensity, and sedentary activity), and potential confounders (activity level, gender, and genderrole continuous scores) were considered as the dependent variable, independent variables, and mediating variables, respectively. Gender differences in PA MET-m/w and depression were conducted using independent sample $t$-test, respectively. Between-group comparisons regarding activity level and gender-role identities categories in PA MET-m/w and/or depression were conducted using one-way ANOVA. The moderation analyses were conducted using the PROCESS by model 1 .

Step 3: To better understand whether and how depression (sum scores of full scale) were impacted by PA MET$\mathrm{m} / \mathrm{w}$ (walking, moderate-intensity, vigorous-intensity, and sedentary activity), age, gender, gender-role continuous scores, grade, the COVID-19-related data among all participants and across different activity levels (LAL, MAL, and HAL), we, therefore, used linear regression to test these models, by the stepwise method. If the significant results were found in One-way ANOVA, the post-hoc comparison would be conducted using Bonferronicorrection. All statistical analyses were conducted using SPSS v22.0 with PROCESS v3.3. ${ }^{47}$ A significance threshold of $p<0.05$ was set when a two-tailed test was used.

\section{Results}

\section{Characteristics of Participants}

Of 625 participants (mean aged 20.18 years, 64.8\% female), 217 (34.72\%) reported depression scores over the cut-off points $(\geq 16$, CES-D). The median (percentiles 25 to 75$)$ MET-m/w in vigorous-, moderate-intensity, walking and sedentary were 0 ( 0 to 240$), 0$ ( 0 to 450 ), 99 (0 to 462) and 2940 (2100 to 3360), respectively. Fiftyeight $(9.28 \%)$ participants were included in the high activity level (HAL) group and 201 (32.16\%) were included in the moderate activity level (MAL) group, while the remaining 368 (58.6\%) participants were included in low activity level (LAL) group. For gender-role identities, 211 (33.76\%), 92 (14.72\%), $80(12.8 \%)$ and 242 (38.72\%) participants were included in undifferentiated, masculine, feminine and androgynous identities, respectively. The characteristics of the participants are reported in Table 1.

\section{Risk of Depression Associated with PA}

As shown in Table 2, depressive symptoms were significantly negatively related to MET-m/w in both vigorous- and moderate-intensity PA, whereas no significant associations of depression with MET-m/w in walking and sedentary were observed.

After controlling for demographic variables (age and grade), MET-m/w in sedentary activity, and data related to the COVID-19 data, results indicated that more time spent on moderate-intensity PA MET-m/w was significantly associated with a lower risk of developing depressive symptoms.

\section{Differences by Activity Level}

Considering that most of the participants reported a lower level of PA in this study, we further compared betweengroup differences of activity levels on depressive symptoms and a significant difference was found $(\mathrm{F}(2,622)=$ 4.32, $\left.p<00.05, \eta_{\mathrm{p}}{ }^{2}=0.014\right)$, indicated that LAL group 
Table I Characteristics of Participants

\begin{tabular}{|l|l|l|l|l|l|l|}
\hline Continuous Variables & n & Mean & SD & Median & $\begin{array}{l}\text { Range } \\
\text { (Percentiles 25 to 75) }\end{array}$ \\
\hline Age & 625 & 20.18 & 1.88 & $/$ & $/$ \\
\hline & \\
\hline
\end{tabular}

IPAQ-SF frequency (days/week, last 7 days)

\begin{tabular}{|l|l|l|l|l|l|l|}
\hline & Vigorous PA & 625 & 1.03 & 1.92 & $/$ & \\
& Moderate PA & 625 & 1.89 & 2.35 & $/$ & $/$ \\
& Walking & 625 & 2.35 & 2.65 & $/$ & $/$ \\
\hline
\end{tabular}

IPAQ-SF duration (minutes/day)

\begin{tabular}{|l|l|l|l|l|l}
\hline Vigorous PA & 625 & 12.95 & 31.09 & $/$ & $/$ \\
Moderate PA & 625 & 20.87 & 30.27 & $/$ & $/$ \\
Walking & 625 & 24.09 & 33.94 & $/$ & $/$ \\
Sedentary & 625 & 418.45 & 183.80 & $/$ & $/$ \\
Moderate-to-Vigorous PA & 625 & 34.82 & 50.82 & $/$ & $/$
\end{tabular}

\section{Depressive symptoms}

\begin{tabular}{|l|l|l|l|l|l}
\hline CES-D score & 625 & 13.48 & 12.26 & $/$ & $/$ \\
Depressed affect & 625 & 5.56 & 5.20 & $/$ & $/$ \\
Positive affect & 625 & 2.63 & 2.89 & $/$ & $/$ \\
Somatic complaints & 625 & 4.48 & 3.97 & $/$ & $/$ \\
Interpersonal problems & 625 & 0.8 & 1.316 & $/$ & $/$ \\
\hline
\end{tabular}

Gender-role scores

\begin{tabular}{|c|c|c|c|c|c|c|}
\hline & $\begin{array}{l}\text { Masculinity scores } \\
\text { Femininity scores }\end{array}$ & $\begin{array}{l}625 \\
625\end{array}$ & $\begin{array}{l}4.80 \\
4.96\end{array}$ & $\begin{array}{l}0.85 \\
0.78\end{array}$ & $\begin{array}{l}1 \\
1\end{array}$ & $\begin{array}{l}1 \\
1\end{array}$ \\
\hline \multicolumn{7}{|c|}{ COVID-I9 data (province level) } \\
\hline & $\begin{array}{l}\text { New cases } \\
\text { Accumulated confirmed cases } \\
\text { Accumulated recovery cases } \\
\text { Accumulated death cases }\end{array}$ & $\begin{array}{l}625 \\
625 \\
625 \\
625\end{array}$ & $\begin{array}{l}0.51 \\
1292.63 \\
1227.01 \\
7.70\end{array}$ & $\begin{array}{l}1.24 \\
243.92 \\
233.50 \\
1.29\end{array}$ & $\begin{array}{l}1 \\
1 \\
1 \\
1\end{array}$ & $\begin{array}{l}1 \\
1 \\
1 \\
1\end{array}$ \\
\hline Categor & ical Variables & $\mathbf{n}$ & $\%$ & & & \\
\hline \multicolumn{7}{|c|}{ PA level categories } \\
\hline & $\begin{array}{l}\text { Low level } \\
\text { Moderate level } \\
\text { High level }\end{array}$ & $\begin{array}{l}366 \\
201 \\
58\end{array}$ & $\begin{array}{l}58.56 \\
32.16 \\
9.28\end{array}$ & & & \\
\hline \multicolumn{7}{|l|}{ Gender } \\
\hline & $\begin{array}{l}\text { Male } \\
\text { Female }\end{array}$ & $\begin{array}{l}220 \\
405\end{array}$ & $\begin{array}{l}35.20 \\
64.80\end{array}$ & & & \\
\hline
\end{tabular}


Table I (Continued).

\begin{tabular}{|c|c|c|c|c|c|}
\hline Continuous Variables & $\mathbf{n}$ & Mean & SD & Median & $\begin{array}{l}\text { Range } \\
\text { (Percentiles } 25 \text { to } 75 \text { ) }\end{array}$ \\
\hline \multicolumn{6}{|l|}{ Gender-Role identities } \\
\hline $\begin{array}{l}\text { Undifferentiated } \\
\text { Masculine } \\
\text { Feminine } \\
\text { Androgynous }\end{array}$ & $\begin{array}{l}211 \\
92 \\
80 \\
242\end{array}$ & $\begin{array}{l}33.76 \\
14.72 \\
12.80 \\
38.72\end{array}$ & & & \\
\hline \multicolumn{6}{|l|}{ Grade } \\
\hline $\begin{array}{l}\text { Gradel } \\
\text { Grade2 } \\
\text { Grade3 } \\
\text { Grade4 } \\
\text { Graduate students }\end{array}$ & $\begin{array}{l}308 \\
142 \\
74 \\
86 \\
15\end{array}$ & $\begin{array}{l}49.28 \\
22.72 \\
11.84 \\
13.76 \\
2.40\end{array}$ & & & \\
\hline \multicolumn{6}{|l|}{ Depression } \\
\hline $\begin{array}{l}\text { Undepressed }(<16) \\
\text { Depressed }(\geq 16)\end{array}$ & $\begin{array}{l}408 \\
217\end{array}$ & $\begin{array}{l}65.28 \\
34.72\end{array}$ & & & \\
\hline
\end{tabular}

reported a significantly higher level of depression than the HAL group (Cohen's $d=0.39$, 95\%C.I. 0.11 to 0.67). As showed in Table 2, significant associations of depression (sum scores and subscale scores related to four dimensions) and MET-m/w of moderate-intensity PA were only observed in the LAL group, but not in the MAL and HAL groups, after controlling for age, gender, gender role, grade, sedentary MET-m/w and COVID-19 data. Furthermore, participants in the LAL group who had a greater amount of MET-m/w in moderate-intensity PA were associated with less depressive symptoms. The moderation effects analysis showed that when LAL group was coded by one and others by zero, the moderation model was significant $(\mathrm{F}(5,619)=3.69, p<0.01$, model- $\mathrm{R}=$ 0.17, model- $\left.\mathrm{R}^{2}=0.03\right)$.

\section{Differs by Gender and Gender Role}

No significant gender differences with respect to depression, MET-m/w of walking and sedentary activity was found, but significant differences according to gender were observed for MET-m/w of moderate-intensity $(\mathrm{t}(390.97)=-3.3, p<0.01)$ and vigorous-intensity PA $(\mathrm{t}(398.89)=-2.74, p<0.01)$. Specifically, females had spent less time on moderate- and vigorous-intensity PA than males. As shown in Table 2, there were significant negative associations between depression and MET-m/w of moderate-intensity PA in males but not in the females.
Males with higher frequency in moderate-intensity PA reported a lower risk of developing depressive mood symptoms (depressed and positive affect). No significant moderation model was found when using gender as the moderator.

For the gender role, significant between-group differences of four identities (undifferentiated, masculine, feminine, and androgynous identities) on depression ( $F(3$, $\left.621)=18.08, \mathrm{p}<0.001, \eta_{\mathrm{p}}{ }^{2}=0.08\right)$ and MET-m/w of walking $\left(\mathrm{F}(3,621)=5.46, \mathrm{p}<0.01, \eta_{\mathrm{p}}{ }^{2}=0\right.$ 0.026) were found. For depression, individuals with undifferentiated $(17.28 \pm 12.98)$ and feminine $(16.9 \pm 12.6)$ identities reported a significantly higher risk of depression than those endorsed with the masculine $(10.95 \pm 10.57)$ and androgynous $(9.98 \pm 10.82)$ identities. For MET-m/w of activities, the individuals with androgynous identity spent more time walking than those endorsed with undifferentiated identity (Cohen's $d=0.35$, 95\%C.I. 0.17 to 0.54 ). However, no significant moderation model was found when using gender role as the moderator.

\section{Linear Regression Models for Depression}

Considering that activity level could directly moderate the associations of depression and MET- $\mathrm{m} / \mathrm{w}$, the linear regression model using stepwise method across activity levels were conducted after a similar analysis regarding all participants (Table 3 ). 
Table 2 Correlations Analyses of CES-D Depressive Symptoms Scores and IPAQ MET-Minutes/Week

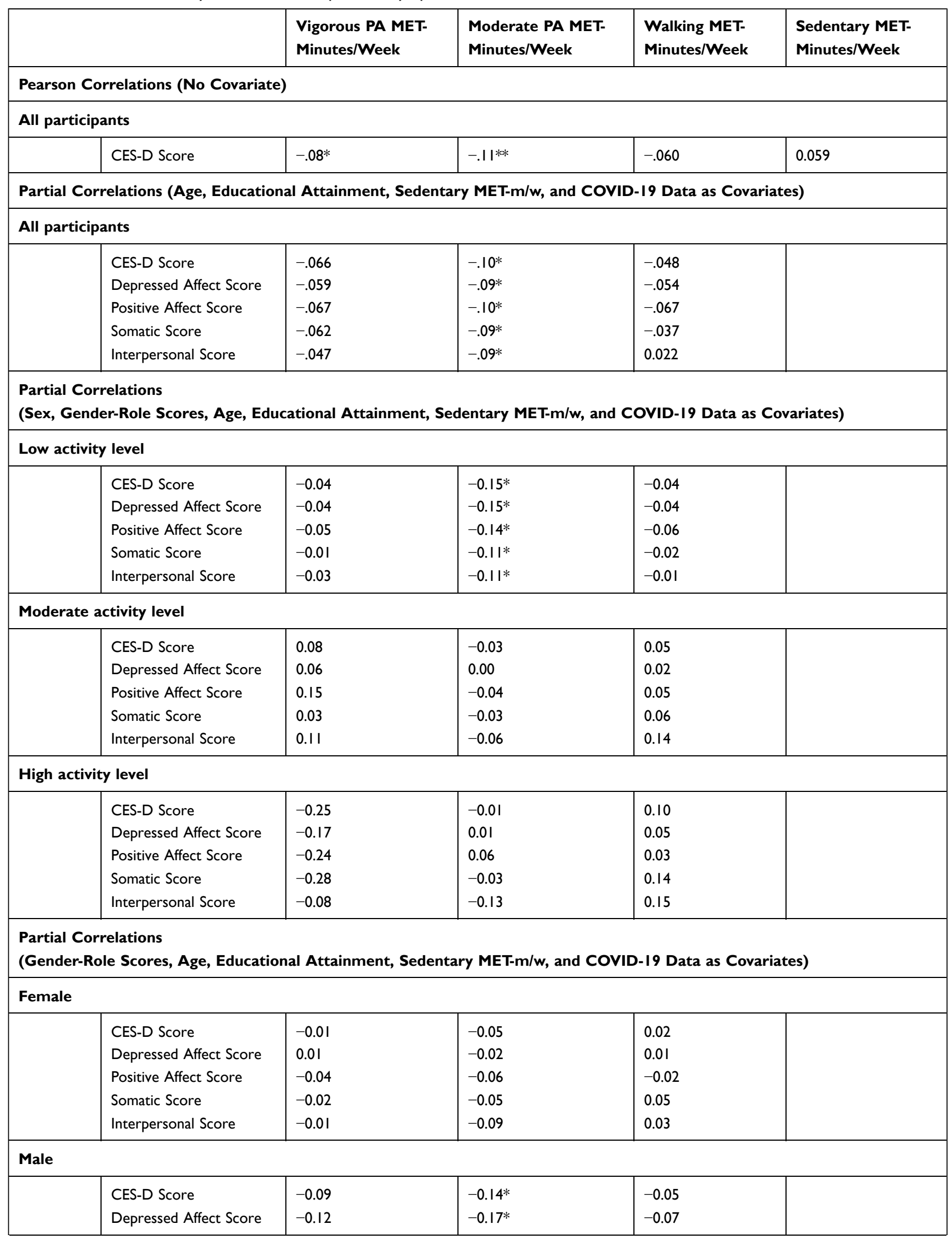


Table 2 (Continued).

\begin{tabular}{|l|l|l|l|l|l|}
\hline \multicolumn{2}{|l|}{} & $\begin{array}{l}\text { Vigorous PA MET- } \\
\text { Minutes/Week }\end{array}$ & $\begin{array}{l}\text { Moderate PA MET- } \\
\text { Minutes/Week }\end{array}$ & $\begin{array}{l}\text { Walking MET- } \\
\text { Minutes/Week }\end{array}$ & $\begin{array}{l}\text { Sedentary MET- } \\
\text { Minutes/Week }\end{array}$ \\
\hline \multirow{2}{*}{} & Positive Affect Score & -0.05 & -0.11 & -0.04 & \\
& Somatic Score & -0.07 & -0.12 & -0.06 & \\
& Interpersonal Score & -0.07 & -0.09 & 0.07 & \\
\hline
\end{tabular}

Notes: ${ }^{*}$ Correlation is significant at the 0.0 I level (2-tailed). $*$ Correlation is significant at the 0.05 level (2-tailed).

For all participants, model 3 that included masculinity score, gender, and moderate-intensity PA as predictors reflects the highest degree of interpretation (Adjusted $\mathrm{R}^{2}=0.10$ ). In this model, masculinity score $(\beta=-0.29)$ and MET-m/w of moderate-intensity PA $(\beta=-0.10)$ were negatively predictive of depression and gender (females were coded as zero, males as 1$)(\beta=0.11)$ were positively predictive of depression.

For the LAL group, model 3 that included masculinity score, gender, and MET-m/w of moderate-intensity PA as predictors reflects the highest degree of interpretation (Adjusted $\left.\mathrm{R}^{2}=0.12\right)$. In this model, masculinity score $(\beta$ $=-0.31)$ and MET- $\mathrm{m} / \mathrm{w}$ of moderate-intensity PA $(\beta=-$ $0.15)$ were negatively predictive of depression and gender (females were coded as zero, males as 1$)(\beta=0.17)$ were positively predictive of depression.

For the MAL group, there was only one significant model $\left(\mathrm{F}(1,199)=4.35, \mathrm{p}<0.05\right.$, Adjusted $\left.\mathrm{R}^{2}=0.02\right)$, in which masculine score was included as predictor variable negatively predicted $(\beta=-0.15)$ depression.

For the HAL group, model 3 that included masculinity score, the number of recovered patients, and death toll as predictors showed the highest degree of interpretation (Adjusted $\mathrm{R}^{2}=0.44$ ). In this model, the masculinity score $(\beta=-0.51)$ and the number of recovered patients $(\beta=-1.63)$ negatively predicted depression, and death toll $(\beta=1.38)$ could positively predict depression.

\section{Discussion}

Results from the present study indicate that more than onethird of college students scored over the cut-off points for clinically relevant depression ( $\geq 16$, CES-D scale), which was consistent with recent publications examining mental health status during the COVID-19 pandemic among young people and college students. ${ }^{12,13}$ Such figures of depression are much higher than the prevalence rate $(3.6 \%)$ at the same age population before the COVID-19 pandemic. $^{11}$ Moreover, results indicate that less time spent on physical activities, which were far below weekly 150-300 minutes of moderate-to-vigorous physical activities during the COVID-
19 pandemic recently recommended by the American College of Sports Medicine (ACSM, 2020). Accordingly, extremely increased depression risk and closure of almost all public places (parks, gym, and schools, etc.) could have significantly decreased time in PA during the COVID-19 pandemic.

More than half of participants were categorized as "low" activity level group in terms of self-reported activity duration and frequency who reported to have a higher level of depression as compared to those in the "high" activity level group. These results were consistent with previous studies investigating the beneficial effects of $\mathrm{PA},{ }^{23,48,49}$ indicating that even under the impact of the COVID-19, PA can also confer protection against increasing levels of depressive symptoms. Furthermore, for the LAL group, moderate MET-m/w showed a robust and significant negative correlation with depressive symptoms regardless of their sedentary time, age, grade, and COVID19 situations. Such findings suggest that individuals should spend more moderate-intensity PA times per week for reducing potential risks of developing depressive symptoms. In contrast, the association between sedentary and depression was not significant. The social withdrawal hypothesis suggests that sedentary behaviors might be associated with an increased risk of depression, which may be attributed to reduced social interactions. ${ }^{50}$ Perhaps this was not the case among the participants in this study, for whom social withdrawal and distancing acted as healthier behavior that reduced the risks of being infected with the COVID-19 and associated psychosocial distress, so the negative effect of higher sedentary might be offset.

In this study, the gender role directly predicted the onset of depression among college students. It is worth noting that this age group who had higher masculinity traits was associated with a lower risk of being depressed. Such results are supported by previous studies, ${ }^{51,52}$ suggesting that masculine traits that include physical and emotional self-control may help them to effectively 


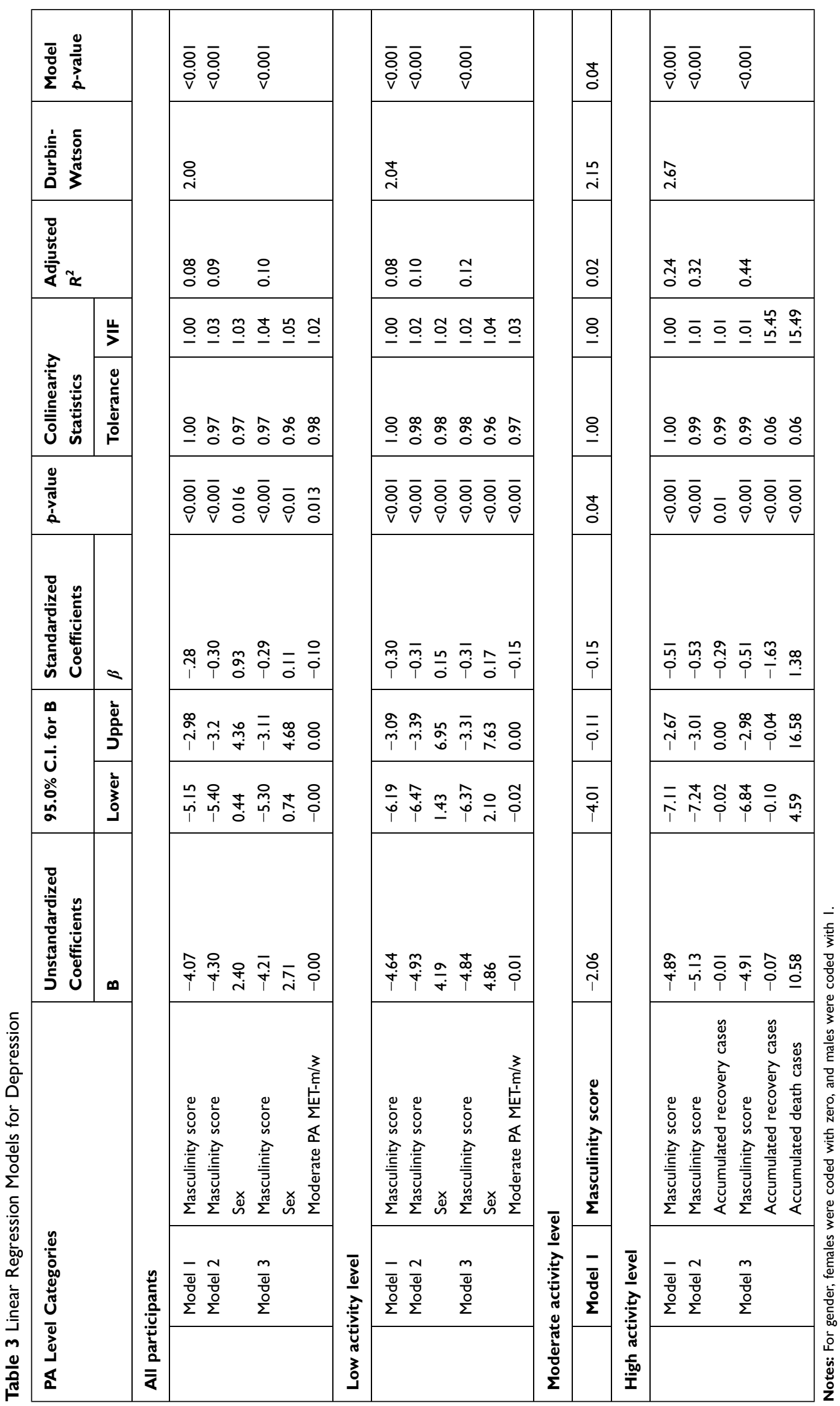


manage and regulate negative emotions during episodes of increased stress exposure such as the pandemic. Multidimensional masculine norms influence individual psychological responses and depressive symptomology over time, ${ }^{53}$ which may inform how pre-existing masculine norms may have contributed to the psychosocial resilience among the study participants. Recently, an imaging study indicated that individuals with higher scores on masculine traits were less sensitive to negative emotional stimuli, ${ }^{54}$ which may in turn, reduce the susceptibility to depression. Most importantly, the predication patterns varied across activity levels.

For the LAL group, less moderate MET-m/w together with low scores on masculinity traits might increase the risk of depression. Moreover, for the HAL, the number of recovered patients and deaths is also predictive of depression in the negative and positive direction, respectively. As indicated by a recent study, specific local outbreak situation (like the number of confirmed cases and recovered cases) was associated with depression in general populations. ${ }^{55}$ Of note, effective control (increased number of recovered cases and decreased number of deaths) of the outbreak could help reduce the risk of developing depression among physically active college students. However, further investigations are still needed to keep a close eye on the dynamic changes for monitoring the onset of depression during life-changing events. Accordingly, college students like LAL who were susceptible to depression are more dependent on their internal factors including masculine traits and moderateintensity PA frequency. In contrast, college students who showed a higher level of physical activity are also susceptible to external factors such as pandemic situations. Collectively, results indicate that individuals with low masculinity traits who showed a "low" level of physical activity may have the greatest vulnerability regardless of gender, which suggests that timely and targeted psychosocial interventions should be implemented for this group during the COVID-19 pandemic.

\section{Practical Implications}

Public health, education departments and school administrators should jointly pay more attention to college students with a lower level of masculinity traits (not specifically females) because they are observed to associate with increased risk of developing depression. Regular moderate-intensity exercises (eg, walking or jogging on a treadmill, using an elliptical trainer, cleaning heavy like washing windows, vacuuming, mopping) should be highly encouraged for depression prevention. Furthermore, findings exercise type that fits those college students with lower masculinity trait should be prioritized as well.

Effective control of the COVID-19 pandemic must be the most critical and ultimate goal of the current policies, however, at the same time measure that may allow attenuating the detrimental effects on mental health such as increasing levels of depression need to flank the measure that aims at reducing the transmission rates by physical distancing. Therefore, international cooperation is essential to stop the spread of the COVID-19 and to prevent long-term negative effects on mental health.

\section{Conclusion}

An increased risk of developing depression is associated with a decreased level of PA during the COVID-19 pandemic. Results suggest that more moderate-intensity MET$\mathrm{m} / \mathrm{w}$ are conducive to achieving mental health benefits college students during this life-changing event. Furthermore, college students endorse fewer masculine traits (regardless of gender) had the greatest susceptibility to depression during this outbreak. The decreased number of deaths and increased recovered patients of COVID-19 would directly lead to a reduced risk of being depressed among general populations.

\section{Acknowledgments}

This study is supported by the following: Shenzhen-Hong Kong Institute of Brain Science-Shenzhen Fundamental Research Institutions (2019SHIBS0003); National Natural Science Foundation of China (31671150; 31871115); Guangdong Key Project (2018B030335001); Guangdong Major Program (2016KZDXM009); Innovative Team Program in Higher Education of Guangdong (2015KCXTD009); Shenzhen Basic Research Scheme (JCYJ20150729104249783); Shenzhen Peacock Plan (KQTD2015033016104926); Clinical Lectureship (ICA-CL-2017-03-001) jointly funded by Health Education England (HEE) and the National Institute for Health Research (NIHR). Brendon Stubbs is part-funded by the NIHR Biomedical Research Centre at South London and Maudsley NHS Foundation Trust. Brendon Stubbs also holds active grants with the Medical Research Council and Guys and St Thomas Charity (GSTT). Brendon Stubbs has received consultancy fees from ASICS Europe BV. The views expressed are those of the author(s) and not necessarily those of the (partner 
organisation), the NHS, the NIHR, the Department of Health and Social Care, the MRC or GSTT.

\section{Disclosure}

The authors report no conflicts of interest in this work.

\section{References}

1. World Health Organization. Coronavirus disease (COVID-19) outbreak; Published 2020. Available from: https://www.who.int/wes ternpacific/emergencies/covid-19. Accessed August 17, 2020.

2. Ritchie H, Ortiz-Ospina E, Beltekian D, et al. Policy responses to the coronavirus pandemic; Published 2020. Available from: https://our worldindata.org/policy-responses-covid. Accessed September 29, 2020.

3. Bao Y, Sun Y, Meng S, Shi J, Lu L. 2019-nCoV epidemic: address mental health care to empower society. Lancet. 2020;395(10224): e37-e38. doi:10.1016/S0140-6736(20)30309-3

4. Shigemura J, Ursano R, Morganstein J, Kurosawa M, Benedek D. Public responses to the novel 2019 coronavirus $(2019-\mathrm{nCoV})$ in Japan: mental health consequences and target populations. Psychiatry Clin Neurosci. 2020;74(4):281-282. doi:10.1111/ pcn. 12988

5. Torales J, O'Higgins M, Castaldelli-Maia J, Ventriglio A. The outbreak of COVID-19 coronavirus and its impact on global mental health. Int J Soc Psychiatry. 2020;66(4):317-320. doi:10.1177/ 0020764020915212

6. Malhi GS, Mann JJ. Depression. Lancet. 2018;392 (10161):2299-2312. doi:10.1016/S0140-6736(18)31948-2

7. World Health Organization. Depression and Other Common Mental Disorders: Global Health Estimates. World Health Organization; 2017.

8. World Health Organization. The Global Burden of Disease: 2004 Update. Geneva: World Health Organization; 2008.

9. Holmes EA, O'Connor RC, Perry VH, et al. Multidisciplinary research priorities for the COVID-19 pandemic: a call for action for mental health science. Lancet Psychiatry. 2020;7(6):547-560. doi:10.1016/S2215-0366(20)30168-1

10. Rogers JP, Chesney E, Oliver D, et al. Psychiatric and neuropsychiatric presentations associated with severe coronavirus infections: a systematic review and meta-analysis with comparison to the COVID-19 pandemic. Lancet Psychiatry. 2020;7(7):611-627. doi:10.1016/S2215-0366(20)30203-0

11. Huang Y, Wang Y, Wang H, et al. Prevalence of mental disorders in China: a cross-sectional epidemiological study. Lancet Psychiatry. 2019;6(3):211-224. doi:10.1016/S2215-0366(18)30511-X

12. Chi X, Becker B, Yu Q, et al. Prevalence and psychosocial correlates of mental health outcomes among chinese college students during the coronavirus disease (covid-19) pandemic. Front Psychiatry. 2020;11:803. doi:10.3389/fpsyt.2020.00803

13. Huang Y, Zhao N. Mental health burden for the public affected by the COVID-19 outbreak in China: who will be the high-risk group? Psychol Health Med. 2020;14:1-12.

14. Xu J, Xu Q, Wang C, Wang J. Psychological status of surgical staff during the COVID-19 outbreak. Psychiatry Res. 2020;288:112955. doi:10.1016/j.psychres.2020.112955

15. Zhang W, Wang K, Yin L, et al. Mental health and psychosocial problems of medical health workers during the covid-19 epidemic in China. Psychother Psychosom. 2020;89(4):242-250. doi:10.1159/ 000507639

16. Wang C, Pan R, Wan X, et al. A longitudinal study on the mental health of general population during the COVID-19 epidemic in China. Brain Behav Immun. 2020;87:40-48. doi:10.1016/j. bbi.2020.04.028
17. Wang X, Hegde S, Son C, Keller B, Smith A, Sasangohar F. Investigating mental health of us college students during the covid-19 pandemic: cross-sectional survey study. $J$ Med Internet Res. 2020;22(9):e22817. doi:10.2196/22817

18. Solomou I, Constantinidou F. Prevalence and predictors of anxiety and depression symptoms during the covid-19 pandemic and compliance with precautionary measures: age and sex matter. Int $J$ Environ Res Public Health. 2020;17:14. doi:10.3390/ ijerph17144924

19. Chi X, Chen S, Chen Y, et al. Psychometric evaluation of the fear of covid-19 scale among chinese population. Int $J$ Ment Health Addict. In press 2020 .

20. Hanson S, Jones A. Is there evidence that walking groups have health benefits? A systematic review and meta-analysis. Br J Sports Med. 2015;49(11):710-715. doi:10.1136/bjsports-2014-094157

21. Kmietowicz Z. Depression is reduced by physical activity, but there's a limit, finds study. BMJ. 2018;362:k3446. doi:10.1136/ bmj.k3446

22. Stubbs B, Koyanagi A, Schuch FB, et al. Physical activity and depression: a large cross-sectional, population-based study across 36 low- and middle-income countries. Acta Psychiatr Scand. 2016;134(6):546-556. doi:10.1111/acps. 12654

23. Schuch F, Vancampfort D, Firth J, et al. Physical activity and incident depression: a meta-analysis of prospective cohort studies. Am $J$ Psychiatry. 2018;175(7):631-648. doi:10.1176/appi.ajp.2018. 17111194

24. American College of Sports Medicine. Staying active during the coronavirus pandemic; Published 2020. Available from: https:// www.exerciseismedicine.org/assets/page_documents/EIM_Rx\%20for $\% 20$ Health_\%20Staying\%20Active $\% 20$ During $\% 20$ Coronavirus $\%$ 20Pandemic.pdf. Accessed September 29, 2020.

25. Hall G, Laddu DR, Phillips SA, Lavie CJ, Arena R. A tale of two pandemics: how will COVID-19 and global trends in physical inactivity and sedentary behavior affect one another? Prog Cardiovasc Dis. 2020;8:S0033-0620(0020)30077-30073.

26. Gallè F, Sabella EA, Ferracuti S, et al. Sedentary behaviors and physical activity of italian undergraduate students during lockdown at the time of covid-19 pandemic. Int J Environ Res Public Health. 2020;17:17. doi:10.3390/ijerph17176171

27. Son C, Hegde S, Smith A, Wang X, Sasangohar F. Effects of covid19 on college students' mental health in the united states: interview survey study. J Med Internet Res. 2020;22(9):e21279. doi:10.2196/ 21279

28. Salk RH, Hyde JS, Abramson LY. Gender differences in depression in representative national samples: meta-analyses of diagnoses and symptoms. Psychol Bull. 2017;143(8):783-822. doi:10.1037/ bul0000102

29. World Health Organization. Physical activity; Published 2018. Available from: https://www.who.int/zh/news-room/fact-sheets /detail/physical-activity. Accessed September 29, 2020.

30. Cretella MA, Rosik CH, Howsepian AA. Sex and gender are distinct variables critical to health: comment on hyde, bigler, joel, tate, and van anders (2019). Am Psychol. 2019;74(7):842-844. doi:10.1037/ amp0000524

31. Small A, Teagno L, Selz K. The relationship of sex role to physical and psychological health. J Youth Adolesc. 1980;9(4):305-314. doi:10.1007/BF02087982

32. Bem SL. The measurement of psychological androgyny. J Consult Clin Psychol. 1974;42(2):155-162. doi:10.1037/h0036215

33. Spence JT, Helmreich R, Stapp J. Ratings of self and peers on sex role attributes and their relation to self-esteem and conceptions of masculinity and femininity. J Pers Soc Psychol. 1975;32(1):29-39. doi: $10.1037 / \mathrm{h} 0076857$

34. Covey LA, Feltz DL. Physical activity and adolescent female psychological development. J Youth Adolesc. 1991;20(4):463-474. doi:10.1007/BF01537186 
35. Li B, Lu B How China made its COVID-19 lockdown work. East Asia Forum; Published 2020. Available from: https://www.eastasia forum.org/2020/04/07/how-china-made-its-covid-19-lockdown-work 1. Accessed September 29, 2020.

36. Bassett DR. International physical activity questionnaire: 12-country reliability and validity. Med Sci Sports Exerc. 2003;35 (8):1381-1395.

37. van Poppel MN, Chinapaw MJ, Mokkink LB, van Mechelen W, Terwee CB. Physical activity questionnaires for adults: a systematic review of measurement properties. Sports Med. 2010;40(7):565-600. doi:10.2165/11531930-000000000-00000

38. Macfarlane DJ, Lee CC, Ho EY, Chan KL, Chan DT. Reliability and validity of the Chinese version of IPAQ (short, last 7 days). J Sci Med Sport. 2007;10(1):45-51. doi:10.1016/j.jsams.2006.05.003

39. Qu N, Li K. Study on the reliability and validity of international physical activity questionnaire (Chinese Vision, IPAQ). Chin J Epidemiol. 2004;25:3.

40. The IPAQ group. guidelines for data processing and analysis of the international physical activity questionnaire; Published 2005. Available from: https://sites.google.com/site/theipaq/scoringprotocol. Accessed September 29, 2020.

41. Ren F, Liu J, Fang Y, Wang M. Measurement invariance of the ces-d in adult sample. Chinese J Clinical Psychology. 2019;27 (5):973-977.

42. Zhang J, Wu Z, Fang G, Li J, Han B, Chen Z. Development of the Chinese age norms of CES-D in urban area. Chinese Mental Health J. 2010;24(2):139-143.

43. Radloff LS. The CES-D scale: a self-report depression scale for research in the general population. Appl Psychol Meas. 1977;1 (3):385-401. doi:10.1177/014662167700100306

44. Liu D, Huang H, Jia F, Gong Q, Huang Q, Li X. A new sex-role inventory (csri-50) indicates changes of sex role among chinese college students. Acta Psychologica Sinica. 2011;43(6):639-649.

45. National Health Commission of the PRC. National health commission of the People's Republic of China. China Daily; Published 2020. Available from: http://www.nhc.gov.cn/xcs/xxgzbd/gzbd_index. shtml. Accessed September 29, 2020.
46. Covid-19 Real-time Tracking. Tencent news; Published 2020. Available from: https://news.qq.com/zt2020/page/feiyan.htm?from= timeline\&isappinstalled $=0 \# /$ ?nojump $=1$. Accessed September 29, 2020.

47. Hayes AF. Introduction to Mediation, Moderation, and Conditional Process Analysis: A Regression-Based Approach. New York, NY, US: Guilford Press; 2013.

48. Liu M, Zhang J, Kamper-DeMarco KE, Hu E, Yao S. Associations of moderate-to-vigorous physical activity with psychological problems and suicidality in Chinese high school students: a cross-sectional study. PeerJ. 2020;8:e8775. doi:10.7717/peerj.8775

49. Pinto Pereira SM, Geoffroy M-C, Power C. Depressive symptoms and physical activity during 3 decades in adult life: bidirectional associations in a prospective cohort study. JAMA Psychiatry. 2014;71(12):1373-1380. doi:10.1001/jamapsychiatry.2014.1240

50. Kraut R, Patterson M, Lundmark V, Kiesler S, Mukopadhyay T, Scherlis W. Internet paradox. A social technology that reduces social involvement and psychological well-being? Am Psychol. 1998;53 (9):1017-1031. doi:10.1037/0003-066X.53.9.1017

51. Juster RP, Pruessner JC, Desrochers AB, et al. Sex and gender roles in relation to mental health and allostatic load. Psychosom Med. 2016;78(7):788-804. doi:10.1097/PSY.0000000000000351

52. Price EC, Gregg JJ, Smith MD, Fiske A. Masculine traits and depressive symptoms in older and younger men and women. $\mathrm{Am}$ J Mens Health. 2018;12(1):19-29. doi:10.1177/1557988315619676

53. Iwamoto DK, Brady J, Kaya A, Park A. Masculinity and depression: a longitudinal investigation of multidimensional masculine norms among college men. Am J Mens Health. 2018;12(6):1873-1881. doi: $10.1177 / 1557988318785549$

54. Yu K, Liao Y, Fu D, et al. Androgyny eliminates sex differences in emotional reactivity: ERP and network coupling evidences. Neurosci Lett. 2020;720:134776. doi:10.1016/j.neulet.2020.134776

55. Wang C, Pan R, Wan X, et al. Immediate psychological responses and associated factors during the initial stage of the 2019 coronavirus disease (covid-19) epidemic among the general population in China. Int J Environ Res Public Health. 2020;17(5):1729. doi:10.3390/ijerph17051729
Psychology Research and Behavior Management

\section{Publish your work in this journal}

Psychology Research and Behavior Management is an international, peer-reviewed, open access journal focusing on the science of psychology and its application in behavior management to develop improved outcomes in the clinical, educational, sports and business arenas. Specific topics covered in the journal include: Neuroscience, memory and decision making; Behavior modification and management; Clinical applications; Business and sports performance management; Social and developmental studies; Animal studies. The manuscript management system is completely online and includes a very quick and fair peer-review system, which is all easy to use. Visit http://www dovepress.com/testimonials.php to read real quotes from published authors. 